\title{
BMJ Open Effects of short-term smoking on lung function and airway hyper- responsiveness in young patients with untreated intermittent adult-onset asthma: retrospective cross-sectional study at a primary-tertiary care hospital in Japan
}

\author{
Kentaro Watai, ${ }^{1,2}$ Kiyoshi Sekiya,${ }^{1}$ Hiroaki Hayashi, ${ }^{1}$ Yuma Fukutomi, ${ }^{1,2}$ \\ Masami Taniguchi ${ }^{1,2}$
}

To cite: Watai K, Sekiya K, Hayashi $\mathrm{H}$, et al. Effects of short-term smoking on lung function and airway hyperresponsiveness in young patients with untreated intermittent adult-onset asthma: retrospective cross-sectional study at a primary-tertiary care hospital in Japan. BMJ Open 2019;9:e023450. doi:10.1136/ bmjopen-2018-023450

- Prepublication history and additional material for this paper are available online. To view these files, please visit the journal online (http://dx.doi. org/10.1136/bmjopen-2018023450).

Received 11 April 2018 Revised 19 February 2019 Accepted 5 April 2019

D) Check for updates

(c) Author(s) (or their employer(s)) 2019. Re-use permitted under CC BY-NC. No commercial re-use. See rights and permissions. Published by BMJ.

For numbered affiliations see end of article.

\section{Correspondence to}

Dr Masami Taniguchi; taniguchi.masami.ne@mail. hosp.go.jp

\begin{abstract}
Objective In daily clinical practice, smokers with asthma and with intermittent disease severity are frequently encountered. The effects of short-term smoking on lung function or disease presentation in younger patients with intermittent adult-onset asthma remain unclear. We sought to clarify the effects of short-term smoking ( $<10$ packyears) on lung function and airway hyper-responsiveness (AHR) in young patients with untreated intermittent adultonset asthma.
\end{abstract}

Design Retrospective, cross-sectional study.

Setting A single primary-tertiary medical centre in Japan. Participants From patients who underwent bronchodilator reversibility tests between January 2004 and March $2011(\mathrm{n}=7291), 262$ consecutive patients (age, 20-34 years) with untreated intermittent adult-onset asthma, including 157 never smokers and 105 current smokers within 10 pack-years, were analysed.

Primary and secondary outcome measures The primary outcome was the association of the daily smoking frequency (number of cigarettes per day), smoking duration (years) and cumulative smoking history (pack-years) with postbronchodilator lung function. The secondary outcome was the association of the former three smoking parameters with AHR.

Results The daily smoking frequency, smoking duration and cumulative smoking history were significantly associated with decreased postbronchodilator lung function. Daily smoking of $\geq 11$ cigarettes per day was also associated with marked AHR (OR 2.23; $95 \% \mathrm{Cl} 1.03$ to 4.80), even after adjustment for age, sex, disease duration and body mass index.

Conclusion Short-term active smoking in early adulthood may be associated with decreased lung function and AHR, even in patients with intermittent adult-onset asthma. Our findings suggest a benefit of never smoking, even for young patients with intermittent adult-onset asthma.
Strengths and limitations of this study

- We focused on young patients (age: 20-34 years) with intermittent adult-onset asthma who had been smoking for $<10$ pack-years.

- We included patients with no history of treatment for asthma to eliminate the effects of treatment on lung function and airway hyper-responsiveness.

- Data were derived from a single centre, and the study was retrospective, which could have caused recall bias.

\section{INTRODUCTION}

Very few studies have demonstrated the effects of smoking on lung function in adult patients with asthma. Because smokers with asthma are generally excluded from surveys to avoid affecting results by including chronic obstructive pulmonary disease (COPD), there are limited number of studies including this patient population. ${ }^{1-4}$ Consequently, the effects of short-term smoking on disease presentation in patients with asthma remain unclear.

Generally, asthma is recognised as a disease that develops in childhood, although adultonset asthma reportedly appears as a dominant phenotype in women by the age of 40 years. ${ }^{5}$ Differentiation of severe asthmatics on the basis of the age at onset identifies the phenotypes of asthma. ${ }^{6}$ Patients with late or adult-onset asthma are frequently non-atopic and exhibit lower lung function than patients with early or childhood-onset asthma, even though the disease duration is shorter in the 
former than in the latter. ${ }^{7}$ Another study identified five clusters of adult-onset asthma: smoking, obesity related, female, atopic and non-rhinitic asthma. The authors found that smoking and obesity-related asthma showed the poorest outcomes and maximum unmet needs in terms of treatment. ${ }^{8}$ Thus, investigation of the effects of smoking in patients with adult-onset asthma is clinically meaningful.

In daily clinical practice, smokers with intermittent asthma are frequently encountered. Some patients with intermittent asthma continue smoking without apparent worsening of symptoms, although we generally encourage all patients with asthma to quit smoking because some studies have shown that long-term smoking results in decreased lung function and a modified disease presentation. ${ }^{9-15}$ However, the effects of short-term active smoking on lung function or disease presentation in a population of younger patients with intermittent adult-onset asthma remain to be elucidated. Data suggesting the benefits of never smoking for young adult patients are expected to provide important basic information for the construction of an asthma education programme.

From these perspectives, we conducted the present study to determine the effects of short-term smoking $(<10$ pack-years) on lung function and airway hyper-responsiveness (AHR) in young patients aged 20-34 years with untreated intermittent adult-onset asthma.

\section{METHODS}

\section{Study design and patients}

This retrospective, cross-sectional study included young patients (age, 20-34 years) with untreated intermittent adult-onset asthma who visited the Department of Allergology at Sagamihara National Hospital for the first time between January 2004 and March 2011.

Figure 1 shows the study flow chart. From patients who underwent bronchodilator reversibility tests between January 2004 and March 2011 (n=7291), those who met the following criteria were included in our study: age, 20-34 years; age at asthma onset, $\geq 16$ years; diagnosis of asthma; presence of intermittent asthma symptoms (symptoms of cough, wheezing, chest tightness or difficulty breathing less than twice a week and night-time symptoms less than twice a month) ${ }^{16}$ and no history of treatment for asthma. To evaluate the direct effect of smoking on lung function, we included patients without childhood asthma, which is a risk factor for persistent airflow limitation. The parents of majority of the patients were not present at the time of examination, so we could only record a surveyed self-reported history of childhood asthma. Moreover, to minimise the likelihood of COPD, we included patients aged $<35$ years. Asthma was diagnosed according to the American Thoracic Society guidelines ${ }^{17}$ and it was defined as recurrent episodes of at least one symptom (paroxysms of dyspnoea, wheezing or cough) associated with airway reversibility (12\% and $200 \mathrm{~mL}$ increase in the forced expiratory volume in one second $\left(\mathrm{FEV}_{1}\right)$ with a short-acting beta 2 agonist and/or increased AHR, represented by a histamine provocative concentration of the agonist causing a decrease in $\mathrm{FEV}_{1}$ by $>20 \%$ (HisPC20) of $<8 \mathrm{mg} / \mathrm{mL}$ ). Intermittent asthma symptoms were defined in accordance with the Global Initiative for Asthma guidelines. ${ }^{16}$ To eliminate the effects of treatment on lung function and AHR, we included patients without history of treatment for asthma.

To evaluate the direct effect of smoking on lung function and AHR, we excluded patients with an abnormal shadow on a chest radiograph, pregnant patients, patients with symptoms of respiratory tract infection and past smokers. Finally, we analysed 262 consecutive patients by reviewing their clinical records. These patients were classified as never smokers and current smokers. Current smokers were stratified into two groups on the basis of the median value for each smoking parameter (number of cigarettes per day, smoking duration in years and cumulative smoking history in pack-years). The smoking history was investigated by an attending physician and a spirometry laboratory technician independently. In daily clinical practice, we carefully investigated the age when the smoking habit started and the number of cigarettes per day, which was the mean number during the previous month. First, an interview was performed by an attending physician at the initial visit. Second, a spirometry laboratory technician investigated the smoking history. If the smoking histories did not match, the spirometry laboratory technician consulted with the patient again to obtain the correct (self-reported) information.

Atopy was defined as a positive skin prick test to extracts of one or more inhalant allergens (including house dust mite, Japanese cedar, timothy, birch, ragweed, mugwort, dog, cat, Alternaria alternata, Aspergillus fumigatus and Cladosporium cladosporioides). ${ }^{18}$ The CAP System FEIA, Fluorescence Enzyme Immuno Assay (Phadia, Uppsala, Sweden) based on ImmunoCAP technology was used for the measurement of total serum IgE according to the manufacturer's instructions.

\section{Outcome variables \\ Lung function}

All patients underwent bronchodilator reversibility tests at their initial visit. In general, patients are asked to avoid taking short-acting inhaled bronchodilators such as salbutamol, a $\beta_{2}$-agonist, within 4 hour of testing. In addition, administration of long-acting beta 2 agonists (LABAs) such as salmeterol and formoterol and oral therapy with aminophylline or slow-release $\beta_{2}$ agonists are discontinued for 12 hours prior to the test. However, in this study, we recruited never-treated patients. First, three acceptable values were recorded for all of the following factors ('pre' values): $\mathrm{FEV}_{1}$, the forced vital capacity (FVC) and the peak expiratory flow (PEF) using a spirometer (Auto Spiro AS-303; Minato Medical Science, Osaka, Japan). 'Acceptable' was defined as follows: enough efforts in all examinations (maximal inspiration, rapid start of exhalation, 


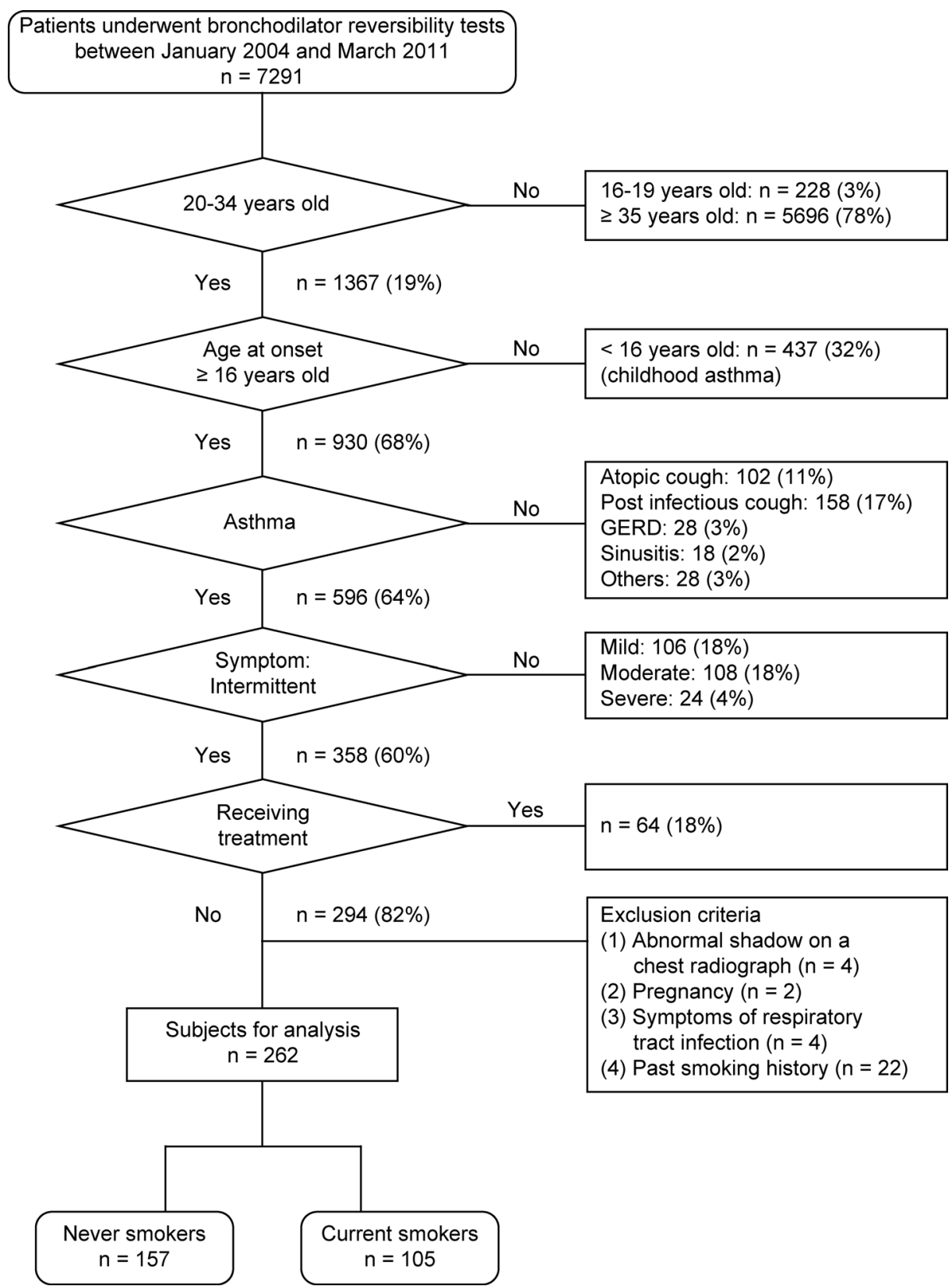

Figure 1 Study flowchart. In total, 7291 patients underwent bronchodilator reversibility tests. Of these, 262 consecutive patients with intermittent adult-onset asthma were analysed via a review of their clinical records. GERD, gastro-esophageal reflux disease.

attainment of PEF, persistence of expiration), absence of artefacts (cough at exhalation, voicing), good start of expiration and adequate exhalation volume. Then, the patient was instructed to inhale four puffs of salbutamol $(100 \mu \mathrm{g}$ each) on separate breaths at $30 \mathrm{~s}$ intervals for a total dose of $400 \mu \mathrm{g}$. Each inhalation involved one puff in one breath to the total lung capacity from a valved spacer device. Finally, three additional acceptable values for $\mathrm{FEV}_{1}, \mathrm{FVC}$ and PEF were recorded $\geq 10 \mathrm{~min}$ and $<15 \mathrm{~min}$ after salbutamol inhalation ('post' values) ${ }^{19}$ Bronchial asthma is characterised by airway reversibility following bronchodilator inhalation. Airway reversibility demonstrates the effectiveness of the bronchodilator. ${ }^{17}$ Therefore, delta $\mathrm{FEV}_{1}(\%)$
( (Postbronchodilator $\mathrm{FEV}_{1}$-prebronchodilator $\left.\mathrm{FEV}_{1}\right) /$ prebronchodilator $\left.\mathrm{FEV}_{1}(\mathrm{~L}) \times 100\right)$ was calculated. ${ }^{19}$ Because irreversible lower lung function is associated with a fixed airflow limitation, 'post'bronchodilator lung function is used as a marker of airway remodelling. ${ }^{20}$ Therefore, the primary outcome was the association of 'post'bronchodilator lung function with daily smoking frequency (number of cigarettes per day), smoking duration (years) and cumulative smoking history (pack-years).

\section{Airway hyper-responsiveness}

Among the 262 patients, 213 underwent a histamine airway challenge test within 1 week after the initial visit, 
whereas the remaining underwent the test within 4 weeks after the initial visit. The AHR test was performed with histamine by tidal breathing method according to a standardised method for challenge testing. ${ }^{21}$ AHR was considered present when HisPC20 was $<8 \mathrm{mg} / \mathrm{mL}$. HisPC20 results of $1-4 \mathrm{mg} / \mathrm{mL}$ and $<1 \mathrm{mg} / \mathrm{mL}$ were considered to indicate mild and moderate to severe AHR, respectively. ${ }^{22}$ We wanted to use the $<1 \mathrm{mg} / \mathrm{mL}$ value as the cut-off point for marked AHR, but the number of patients who showed AHR below $1 \mathrm{mg} / \mathrm{mL}$ was small, and the median (IQR) HisPC20 value was $1.99 \mathrm{mg} / \mathrm{mL}(0.89-4.10)$. In some previous studies, $2 \mathrm{mg} / \mathrm{mL}$ was used as the cut-off point. ${ }^{23}$ Therefore, we decided to use a cut-off HisPC20 value of $2 \mathrm{mg} / \mathrm{mL}$ to define marked AHR.

\section{Statistical analyses}

The collected data were analysed using SPSS V.21.0 software (IBM). Demographic variables, the age at onset, the duration of asthma and the proportion of atopic patients were compared among never smokers, current smokers with a greater smoking history and current smokers with a lesser smoking history. The statistical significance of differences in normally and non-normally distributed continuous variables among the three groups was analysed using analysis of variance and the Kruskal-Wallis test, respectively. The $\chi^{2}$ test was used to determine whether the distributions of categorical variables exhibited significant differences. The smoking parameters were collinear, so they could not be included in the same model. The association between postbronchodilator lung function and smoking parameter was evaluated using multiple linear regression analysis adjusted for age, sex, disease duration and body mass index (BMI). Non-normally distributed covariates were $\log$ transformed. Moreover, we validated the models by confirming that the residuals were normally distributed. The effect of smoking on AHR was also evaluated using multivariate logistic regression analysis adjusted for age, sex, disease duration and BMI. A $p$ value of $<0.05$ was considered statistically significant.

\section{RESULTS}

\section{Patient characteristics}

We focused on short-term smoking, and the median (IQR) number of pack-years was $4.0(2.0-6.3)$ for all current smokers. The clinical characteristics of the patients stratified on the basis of the number of pack-years are shown in table 1 . There was no significant difference in the duration of asthma or proportion of atopic patients among the three groups. The age at examination, age at asthma onset, sex ratio and peripheral blood eosinophil count showed significant differences among the three groups, whereas the serum total IgE level showed no significant differences. Online supplementary tables S1 and S2 show the characteristics of patients stratified by the number of cigarettes per day and the duration of smoking, respectively. There were no significant differences in parameters except for the age at examination and asthma onset among the three tables.

Dose-dependent association between the smoking parameter and postbronchodilator lung function

Table 2 shows the association between the smoking parameter and postbronchodilator lung function, determined using multiple linear regression analysis adjusted for age, sex, disease duration (log transformed) and BMI. The smoking parameters were collinear, so they could not be included in the same model. Current smokers were stratified into two groups on the basis of the median value for each smoking parameter (current smokers with a greater smoking history and lesser smoking history).

The postbronchodilator lung function of current smokers was significantly lower than that of never smokers, even though the smoking history was $<10$ pack-years.

Although similar results were obtained for all three smoking parameters, we have showed the R-squared $\left(\mathrm{R}^{2}\right)$ for each regression equation in table 2. The duration of smoking showed the highest $R^{2}$ among the three smoking parameters.

\section{Association between the smoking parameter and AHR}

Among the 262 patients, 213 underwent a histamine airway challenge test (HisPC20: median (IQR), 1.99 $(0.89-4.10))$; HisPC20 was $<2 \mathrm{mg} / \mathrm{mL}$ and $\geq 2 \mathrm{mg} / \mathrm{mL}$ for 107 and 106 patients, respectively. The association between marked AHR (HisPC20 $<2 \mathrm{mg} / \mathrm{mL}$ ) and the smoking parameter, determined using multivariate logistic regression analysis adjusted for age, sex disease duration (log transformed) and BMI is shown in table 3. The smoking parameters were collinear, so they could not be included in the same model. Therefore, we created three separate models. Among the smoking parameters, only the number of cigarettes per day remained significant. The OR for marked AHR in the $\geq 11$ cigarettes/day group was $2.23(95 \% \mathrm{CI}) 1.03$ to 4.80$)$. Moreover, the association between the number of cigarettes per day and marked AHR showed the highest pseudo $\mathrm{R}^{2}$ result.

Patient and public involvement

There was no patient and public involvement.

\section{DISCUSSION}

In the present study, we demonstrated that short-term active smoking $(<10$ pack-years $)$ in young patients with untreated intermittent adult-onset asthma was associated with decreased lung function and AHR. The daily smoking frequency (number of cigarettes per day), smoking duration (years) and cumulative smoking history (pack-years) were significant predictors of a decreased lung function, even though the patients were young adults with intermittent asthma. Furthermore, the daily smoking frequency remained as an independent determinant of marked AHR (HisPC20 $<2 \mathrm{mg} / \mathrm{mL}$ ). Collectively, these findings suggest 
Table 1 Characteristics of young patients with untreated intermittent adult-onset asthma who were categorised by the cumulative smoking history (pack-years)

\begin{tabular}{|c|c|c|c|c|}
\hline & \multicolumn{3}{|c|}{ Cumulative smoking history (pack-years) } & \multirow[b]{2}{*}{$P$ value } \\
\hline & $\begin{array}{l}\text { Never } \\
(n=156)\end{array}$ & $\begin{array}{l}0<\text { pack-years } \leq 4^{*} \\
(n=55)\end{array}$ & $\begin{array}{l}>4 \text { pack-years } \\
(n=51)\end{array}$ & \\
\hline Age (years) & $26.9 \pm 4.7$ & $26.9 \pm 3.9$ & $29.0 \pm 2.7$ & $<0.001$ \\
\hline Age at onset (years) & $24.9 \pm 5.0$ & $23.8 \pm 4.5$ & $26.9 \pm 3.9$ & 0.001 \\
\hline Men, n (\%) & $35(22.4)$ & $15(27.3)$ & $24(47.1)$ & 0.003 \\
\hline Duration of asthma (months) & $10(2-36)$ & $12(2-60)$ & $12(2-36)$ & 0.448 \\
\hline $\mathrm{BMI}, \mathrm{kg} / \mathrm{m}^{2}$ & $21.6 \pm 3.4$ & $22.4 \pm 4.5$ & $21.9 \pm 3.3$ & 0.337 \\
\hline Total IgE (IU/mL) & $164(70-537)$ & $217(55-721)$ & $248(78-807)$ & 0.243 \\
\hline Peripheral blood eosinophil (count) & $230(105-405)$ & $290(160-490)$ & $350(250-700)$ & 0.016 \\
\hline Atopy, n (\%) & $138(89)$ & $47(86)$ & $50(98)$ & 0.075 \\
\hline \multicolumn{5}{|l|}{ Prebronchodilator lung function } \\
\hline $\mathrm{FEV}_{1}(\%$ predicted $)$ & $96.4 \pm 12.6$ & $89.9 \pm 10.3$ & $90.6 \pm 15.5$ & $<0.001$ \\
\hline $\mathrm{FEV}_{1} / \mathrm{FVC}$ ratio & $0.85 \pm 0.07$ & $0.82 \pm 0.08$ & $0.80 \pm 0.08$ & $<0.001$ \\
\hline $\mathrm{FVC}(\mathrm{L})$ & $3.50 \pm 0.70$ & $3.49 \pm 0.83$ & $3.82 \pm 0.92$ & 0.053 \\
\hline FVC (\%) & $107 \pm 12.7$ & $103 \pm 17.6$ & $106 \pm 15.0$ & 0.187 \\
\hline $\mathrm{FEF}_{25-75}(\%$ predicted $)$ & $76.3 \pm 22.4$ & $65.0 \pm 17.8$ & $65.8 \pm 23.0$ & $<0.001$ \\
\hline \multicolumn{5}{|l|}{ Postbronchodilator lung function } \\
\hline $\mathrm{FEV}_{1}(\%$ predicted $)$ & $101 \pm 14.7$ & $96.2 \pm 12.2$ & $92.4 \pm 22.4$ & 0.025 \\
\hline $\mathrm{FEV}_{1} / \mathrm{FVC}$ ratio & $0.89 \pm 0.07$ & $0.87 \pm 0.07$ & $0.81 \pm 0.10$ & $<0.001$ \\
\hline $\mathrm{FEF}_{25-75}(\%$ predicted $)$ & $89.2 \pm 21.3$ & $80.1 \pm 19.9$ & $75.5 \pm 26.6$ & 0.001 \\
\hline$\Delta \mathrm{FEV}_{1}(\%) \dagger$ & $4.89 \pm 12.6$ & $7.58 \pm 7.90$ & $7.78 \pm 5.24$ & 0.151 \\
\hline HisPC20 (mg/mL) & $2.52(1.05-4.50)$ & $1.63(0.40-3.28)$ & $1.48(0.64-2.55)$ & 0.003 \\
\hline
\end{tabular}

Data are presented as means \pm SD, $n(\%)$ or medians (IQRs).

Postbronchodilator FVC is missing value, therefore, the data are not shown.

Results highlighted in bold indicate statistically significant findings.

${ }^{*}$ Current smokers were stratified on the basis of the median value for each smoking parameter.

$\dagger\left(\right.$ Postbronchodilator FEV -prebronchodilator $\mathrm{FEV}_{1}$ )/prebronchodilator $\mathrm{FEV}_{1}(\mathrm{~L}) \times 100$.

$\mathrm{BMI}$, body mass index; $\mathrm{FEF}_{25-75}$, forced expiratory flow between $25 \%$ and $75 \%$ of the vital capacity; $\mathrm{FEV}_{1}$, forced expiratory volume in one second; FVC, forced vital capacity; HisPC20, provocative concentration of histamine leading to a decrease in the FEV , by $>20 \%$.

a benefit of never smoking even for young patients with intermittent adult-onset asthma.

Our study showed the effects of short-term smoking $(<10$ pack-years $)$ in patients with adult-onset asthma and revealed that a cumulative smoking history of $<10$ pack years was associated with lower lung function not fully responsive to bronchodilator and marked AHR. Epidemiological evidence suggests that a smoking history of $\geq 10$ pack-years causes an accelerated decline in lung function in patients with adult asthma. ${ }^{23}$ Elderly current smokers with asthma who have a prolonged high packyears (mean $\pm \mathrm{SD}, 41 \pm 23$ ) comprise a population that is at high risk of severe or life-threatening disease exacerbation, regardless of the relatively small disease duration. ${ }^{24}$ Although our study is not a longitudinal study, it can be considered to be at the lower end of a continuum of studies reporting lung function declines in adult patients with asthma and a relevant smoking history. Even after the inhalation of a bronchodilator, there was a significant difference in lung function between the never smokers and current smokers in our study. This finding indicates that even a short smoking duration $(<10$ packyears) is associated with a future risk of persistent airflow limitation.

The smoking duration exhibited the highest $R^{2}$ in the multiple linear regression analysis adjusted for age, sex, disease duration and BMI. This finding suggests that the smoking duration can have a profound effect on lung function when compared with the results of other smoking parameters (cigarettes per day and pack-years). However, the prediction accuracy of the models is not very high. This implies that the influence of smoking may vary among individuals.

The $\triangle \mathrm{FEV}_{1}$ before and after bronchodilator inhalation tended to be higher for smokers than for never smokers, but the difference was not statistically significant. This was because the smoking group exhibited poor lung function at baseline, but statistical significance was not shown owing to the small sample size of this study. However, even after bronchodilator inhalation, postbronchodilator lung 
Table 2 Multiple linear regression analysis for the association between postbronchodilator lung function and the smoking status in young patients with untreated intermittent adult-onset asthma

\begin{tabular}{|c|c|c|c|c|}
\hline \multirow[b]{4}{*}{$\begin{array}{l}\text { Postbronchodilator lung } \\
\text { function, (continuous) }\end{array}$} & \multicolumn{3}{|c|}{ Number of cigarettes per day } & \multirow[b]{4}{*}{ Adjusted $\mathbf{R}^{2}$} \\
\hline & \multicolumn{2}{|c|}{ Never smoker 1-10† } & \multirow{2}{*}{$\begin{array}{l}\geq 11 \\
n=51\end{array}$} & \\
\hline & $n=156$ & $\mathrm{n}=55$ & & \\
\hline & (Ref.) & $\begin{array}{l}\text { Partial regression coefficient } \\
(95 \% \mathrm{Cl})\end{array}$ & $\begin{array}{l}\text { Partial regression coefficient } \\
(95 \% \mathrm{Cl})\end{array}$ & \\
\hline $\mathrm{FEV}_{1}(\%$ predicted $)$ & 0 & $-6.72(-12.0 \text { to }-1.41)^{*}$ & $-7.76(-13.7 \text { to }-1.81)^{*}$ & 0.032 \\
\hline $\mathrm{FEV}_{1} / \mathrm{FVC}$ ratio & 0 & $-0.032(-0.062 \text { to }-0.001)^{*}$ & $-0.040(-0.079 \text { to }-0.001)^{*}$ & 0.170 \\
\hline \multirow{4}{*}{$\mathrm{FEF}_{25-75}(\%$ predicted $)$} & 0 & $-9.77(-17.2 \text { to }-2.38)^{*}$ & $-10.4(-18.7 \text { to }-2.15)^{*}$ & 0.045 \\
\hline & \multicolumn{3}{|c|}{ Duration of smoking (years) } & \\
\hline & Never & $1-7$ years $†$ & $\geq 8$ years & \\
\hline & $\mathrm{n}=156$ & $n=49$ & $\mathrm{n}=57$ & \\
\hline $\mathrm{FEV}_{1}(\%$ predicted) & 0 & $-2.89(-8.64$ to 2.86$)$ & $-11.1(-16.6 \text { to }-5.63)^{* *}$ & 0.054 \\
\hline $\mathrm{FEV}_{1} / \mathrm{FVC}$ ratio & 0 & $-0.012(-0.049$ to. 026$)$ & $-0.049(-0.080 \text { to }-0.017)^{\star \star}$ & 0.186 \\
\hline \multirow[t]{4}{*}{$\mathrm{FEF}_{25-75}(\%$ predicted $)$} & 0 & $-6.49(-14.6$ to 1.61$)$ & $-13.2(-20.9 \text { to }-5.47)^{\star *}$ & 0.053 \\
\hline & \multicolumn{3}{|c|}{ Cumulative consumption, pack-years } & \\
\hline & Never & $0<$ pack years $\leq 4 \dagger$ & $>4$ pack-years & \\
\hline & $\mathrm{n}=156$ & $\mathrm{n}=55$ & $\mathrm{n}=51$ & \\
\hline $\mathrm{FEV}_{1}(\%$ predicted) & 0 & $-5.29(-10.6 \text { to }-0.005)^{*}$ & $-9.91(-15.9 \text { to }-3.97)^{\star \star}$ & 0.039 \\
\hline $\mathrm{FEV}_{1} / \mathrm{FVC}$ ratio & 0 & $-0.021(-0.052$ to 0.001$)$ & $-0.055(-0.091 \text { to }-0.018)^{\star *}$ & 0.185 \\
\hline $\mathrm{FEF}_{25-75}(\%$ predicted $)$ & 0 & $-8.85(-16.3 \text { to }-1.43)^{*}$ & $-11.7(-20.0 \text { to }-3.35)^{\star \star}$ & 0.047 \\
\hline
\end{tabular}

Each lung function parameter was separately analysed after adjustment for sex, age, disease duration (log transformed) and BMI.

Each partial regression coefficient shows the difference between mean values and those for never smokers after adjustment for sex, age, disease duration (log transformed) and BMI.

Results highlighted in bold indicate statistically significant findings.

${ }^{*} \mathrm{P}<0.05,{ }^{*} \mathrm{P}<0.01$ versus never smoker.

†Current smokers were stratified on the basis of the median value for each smoking parameter.

$\mathrm{BMI}$, body mass index; $\mathrm{FEV}_{1}$, forced expiratory volume in one second ; FVC, forced vital capacity ; $\mathrm{FEF}_{25-75}$, forced expiratory flow between 25

$\%$ and $75 \%$ of the vital capacity .

function was significantly lower in smokers than in never smokers. Thus, smoking cessation is mandatory even for patients with intermittent adult-onset asthma.

The reason for increased peripheral blood cells in smokers with asthma remains unknown. In a previous cluster analysis, ${ }^{8}$ a cluster of patients with adult-onset asthma and the strongest history of smoking (smoking asthma) was identified, and this was the only group that showed no decrease in blood eosinophils from diagnosis to the 12 year follow-up. On the other hand, patients with asthma-COPD overlap in another study showed higher blood neutrophil levels than did patients with adult-onset asthma. ${ }^{25}$ These findings indicate an alteration in the inflammatory cell response in smokers with asthma. The generation of leukotriene B4 by peripheral blood leucocytes is greater in smokers with asthma than in never smokers with asthma. ${ }^{26}$ We wanted to examine differences in the effects of smoking on lung function between patients with atopic asthma and those with non-atopic asthma; however, the number of patients with non-atopic asthma was too small for statistical analysis.
Intriguingly, only the number of cigarettes per day, and not the duration of smoking and cumulative consumption, was a significant predictor of marked AHR (HisPC20<2 mg/mL) in our study, even after adjusting for age, sex, disease duration and BMI. Moreover, the association between the number of cigarettes per day and marked AHR showed the highest pseudo $\mathrm{R}^{2}$. These findings suggest that the number of cigarettes smoked per day has a greater effect on AHR than the smoking duration. As noted earlier, it may be that the influence of smoking may vary among individuals. AHR could be influenced by acute inflammatory stimuli with daily cigarette smoke, whereas persistent airflow limitation may be more closely associated with chronic exposure. Juusela $e t a l^{27}$ reported that a smoking history of at least 8.5 pack-years yielded an OR of 2.65 (95\% CI 1.40 to 5.00) for AHR (the provocative dose of histamine inducing a fall of $\mathrm{FEV}_{1}$ by $15 \%\left(\mathrm{PD}_{15} \mathrm{FEV}_{1}\right.$ value) $\leq 1.6 \mathrm{mg}$ ), while a history of $<8.5$ pack-years yielded an OR of 0.75 (95\% CI 0.31 to 1.83). The mean age of the subjects enrolled in their study was $46.4 \pm 10.2$ years, and the mean cumulative smoking history was $8.51 \pm 11.3$ 
Table 3 Multivariate logistic regression analysis of factors associated with marked airway hyper-responsiveness (HisPC20<2 $\mathrm{mg} / \mathrm{mL}$ ) in young patients with untreated intermittent adult-onset asthma

\begin{tabular}{|c|c|c|c|c|c|}
\hline & (Reference) & $\begin{array}{l}\text { Adjusted† OR } \\
(95 \% \mathrm{Cl})\end{array}$ & $P$ value & $\begin{array}{l}\text { Adjusted† OR } \\
(95 \% \mathrm{Cl})\end{array}$ & $P$ value \\
\hline & \multicolumn{5}{|c|}{ Number of cigarettes per day (pseudo $\left.R^{2} \ddagger=0.064\right)$} \\
\hline & $n=137$ & $\mathrm{n}=39$ & & $\mathrm{n}=37$ & \\
\hline \multirow[t]{2}{*}{ HisPC20<2 mg/mL } & 1 & 1.43 (0.68 to 3.00$)$ & 0.341 & $2.23(1.03 \text { to } 4.80)^{*}$ & 0.041 \\
\hline & $n=137$ & $\mathrm{n}=36$ & & $n=40$ & \\
\hline \multirow[t]{3}{*}{ HisPC20<2 mg/mL } & 1 & 1.72 (0.80 to 3.67$)$ & 0.164 & 1.83 (0.85 to 3.94$)$ & 0.120 \\
\hline & \multicolumn{5}{|c|}{ Cumulative consumption, pack-years (pseudo $R^{2} \ddagger=0.059$ ) } \\
\hline & Never smoker & $0<$ pack-years $\leq 4 \S$ & & >4 pack-years & \\
\hline
\end{tabular}

Results highlighted in bold indicate statistically significant findings.

${ }^{*} \mathrm{P}<0.05$.

$\dagger$ Adjusted for sex, age, disease duration (log transformed) and BMI.

$\ddagger$ McFadden.

§Current smokers were stratified on the basis of the median value for each smoking parameter.

$\mathrm{BMI}$, body mass index; HisPC20, provocative concentration of histamine leading to a decrease in the forced expiratory volume in $1 \mathrm{~s}$ by $>20 \%$.

pack-years. The $>4$ pack year group $(\mathrm{n}=38)$ in our study did not show a significant OR for marked AHR (OR 1.96 (95\% CI 0.90 to 4.26), $\mathrm{p}=0.09$ ); Our finding regarding the association between pack-years and marked AHR are consistent with the finding of Juusela $e t a l^{27}$ but was not significant, which could be due to the small number of events. Our findings suggest that marked AHR could be caused even by a lower pack-year history. The non-specific AHR to methacholine is higher in women than in men. ${ }^{28}$ In the present study, there were no significant sex-related differences in lung function and AHR (data not shown).

The strength of our study is that we focused on adultonset asthma with short smoking history ( $<10$ pack-years) and excluded patients with childhood asthma, which is a risk factor for persistent airflow limitation, to evaluate the direct effects of smoking on lung function, ${ }^{29}$ even though Hancox $e t a l^{30}$ found no evidence of additive or multiplicative effects of childhood-persistent asthma on airflow obstruction. Moreover, to minimise the likelihood of including patients with COPD, we only included patients aged $<35$ years.

This study has some limitations. First, this was a cross-sectional study that cannot yield insight into the causal relationship between smoking and the outcomes measured. Second, bronchodilator response and/or AHR were used as both inclusion criteria and outcome variables, which could have led to bias that may limit the generalisability of the findings. Third, the effect of smoking cessation on lung function and AHR was not evaluated. Young smokers with intermittent asthma exhibit low rates of smoking cessation. Moreover, the median time until smoking cessation is 17 years among adults with asthma. ${ }^{31}$ Therefore, the effects of active cigarette smoking, even for a short term, on the lung function of young adult patients with intermittent asthma was worth clarifying in this study. Fourth, we did not evaluate the effects of childhood or current passive smoking on the lung function of never smokers. The risk of smoking among children residing with parents who are persistent heavy smokers is particularly high. ${ }^{32}$ Cigarette smoking by parents causes a significant increase in interleukin (IL)-13 secretion in the airway of children with allergic asthma. ${ }^{33}$ In a previous study, male children of smoking parents exhibited a significantly higher total eosinophil count and percentage and higher IgE levels compared with male children of non-smoking parents. ${ }^{34}$ Fifth, we included patients aged $<35$ years to minimise the likelihood of COPD, however, it is possible, even likely, that some of our patients had mild COPD which could explain (in whole or in part) our results $\left(\mathrm{FEV}_{1}\right.$ and HisPC20) independent of the asthma. Sixth, although we carefully determined the smoking history and history of childhood asthma, both were self-reported by the patients. Therefore, there is a possibility that patients with subclinical childhood asthma were included in this study. Finally, the sample size was small. Therefore, our study may not have had enough power for the detection of some associations between smoking parameters and lung function and between smoking parameters and marked AHR.

In conclusion, the findings of this study suggest that short-term active smoking in early adulthood is associated with decreased lung function and AHR, even in patients with intermittent asthma. Thus, never smoking 
would benefit even young patients with intermittent adult-onset asthma. Data regarding these benefits will provide important basic information for the construction of asthma education programmes.

\section{Author affiliations}

${ }^{1}$ Clinical Research Center for Allergy and Rheumatology, National Hospital Organization Sagamihara National Hospital, Kanagawa, Japan

${ }^{2}$ Course of Allergy and Clinical Immunology, Juntendo University Graduate School of Medicine, Tokyo, Japan

Contributors MT and KS: conception or design of the study. KS, HH and KW: acquisition, analysis or interpretation of data. KW and YF: drafting the work (writing the manuscript) or revising it critically for important intellectual content. MT: final approval of the version to be published.

Funding The authors have not declared a specific grant for this research from any funding agency in the public, commercial or not-for-profit sectors.

Competing interests None declared.

Patient consent for publication Not required.

Ethics approval The Research Ethics Committee of Sagamihara National Hospital approved the study protocol, which included an opt-out consent policy (№ 3 in 2013).

Provenance and peer review Not commissioned; externally peer reviewed.

Data sharing statement № additional data are available.

Open access This is an open access article distributed in accordance with the Creative Commons Attribution Non Commercial (CC BY-NC 4.0) license, which permits others to distribute, remix, adapt, build upon this work non-commercially, and license their derivative works on different terms, provided the original work is properly cited, appropriate credit is given, any changes made indicated, and the use is non-commercial. See: http://creativecommons.org/licenses/by-nc/4.0/.

\section{REFERENCES}

1. Polosa R, Thomson NC. Smoking and asthma: dangerous liaisons. Eur Respir J 2013;41:716-26.

2. Çolak Y, Afzal S, Nordestgaard BG, et al. Characteristics and prognosis of never-smokers and smokers with asthma in the Copenhagen General Population Study. A Prospective Cohort Study. Am J Respir Crit Care Med 2015;192:172-81.

3. Tommola M, Ilmarinen P, Tuomisto LE, et al. The effect of smoking on lung function: a clinical study of adult-onset asthma. Eur Respir $J$ 2016;48:1298-306.

4. Tuomisto LE, Ilmarinen $\mathrm{P}$, Niemelä $\mathrm{O}$, et al. A 12-year prognosis of adult-onset asthma: Seinäjoki Adult Asthma Study. Respir Med 2016;117:223-9.

5. Sood A, Qualls C, Schuyler M, et al. Adult-onset asthma becomes the dominant phenotype among women by age 40 years. the longitudinal CARDIA study. Ann Am Thorac Soc 2013;10:188-97.

6. Wenzel SE. Asthma phenotypes: the evolution from clinical to molecular approaches. Nat Med 2012;18:716-25.

7. Miranda C, Busacker A, Balzar S, et al. Distinguishing severe asthma phenotypes: role of age at onset and eosinophilic inflammation. $J$ Allergy Clin Immunol 2004;113:101-8.

8. Ilmarinen P, Tuomisto LE, Niemelä O, et al. Cluster analysis on longitudinal data of patients with adult-onset asthma. J Allergy Clin Immunol Pract 2017;5:967-78.

9. Siroux V, Pin I, Oryszczyn MP, et al. Relationships of active smoking to asthma and asthma severity in the EGEA study. Eur Respir $J$ 2000;15:470-7.

10. Chalmers GW, Macleod KJ, Little SA, et al. Influence of cigarette smoking on inhaled corticosteroid treatment in mild asthma. Thorax 2002;57:226-30.

11. Silverman RA, Boudreaux ED, Woodruff PG, et al. Cigarette smoking among asthmatic adults presenting to 64 emergency departments. Chest 2003;123:1472-9.
12. Chaudhuri R, Livingston E, McMahon AD, et al. Cigarette smoking impairs the therapeutic response to oral corticosteroids in chronic asthma. Am J Respir Crit Care Med 2003;168:1308-11.

13. Tomlinson JE, McMahon AD, Chaudhuri R, et al. Efficacy of low and high dose inhaled corticosteroid in smokers versus non-smokers with mild asthma. Thorax 2005;60:282-7.

14. Lazarus SC, Chinchilli VM, Rollings NJ, et al. Smoking affects response to inhaled corticosteroids or leukotriene receptor antagonists in asthma. Am J Respir Crit Care Med 2007;175:783-90.

15. Kane B, Kolsum U, Southworth T, et al. The effects of smoking on the lipopolysaccharide response and glucocorticoid sensitivity of alveolar macrophages of patients with asthma. Chest 2009;136:163-70.

16. GINA Report. Global Strategy for Asthma Management and Prevention. 2015 http://ginasthma.org/wp-content/uploads/2016/01/ GINA_Report_2015_Aug11-1.pdf (Accessed 22 Nov 2017).

17. American Thoracic Society. Statement on standards for the diagnosis and care of patients with Chronic Obstructive Pulmonary Disease (COPD) and asthma. Am Rev Respir Dis 1987;136:225-44.

18. Johansson SG, Hourihane JO, Bousquet J, et al. A revised nomenclature for allergy. An EAACI position statement from the EAACI nomenclature task force. Allergy 2001;56:813-24.

19. Miller MR, Hankinson J, Brusasco V, et al. Standardisation of spirometry. Eur Respir J 2005;26:319-38.

20. Rasmussen F, Taylor DR, Flannery EM, et al. Risk factors for airway remodeling in asthma manifested by a low postbronchodilator FEV / vital capacity ratio: a longitudinal population study from childhood to adulthood. Am J Respir Crit Care Med 2002;165:1480-8.

21. Sterk PJ, Fabbri LM, Quanjer PH, et al. Airway responsiveness. Standardized challenge testing with pharmacological, physical and sensitizing stimuli in adults. Report Working Party Standardization of Lung Function Tests, European Community for Steel and Coal. Official Statement of the European Respiratory Society. Eur Respir J Suppl 1993;16:53-83.

22. Crapo RO, Casaburi R, Coates AL, et al. Guidelines for methacholine and exercise challenge testing-1999. This official statement of the American Thoracic Society was adopted by the ATS Board of Directors, July 1999. Am J Respir Crit Care Med 2000;161:309-29.

23. Van Schayck CP, Dompeling E, Van Herwaarden CL, et al. Interacting effects of atopy and bronchial hyperresponsiveness on the annual decline in lung function and the exacerbation rate in asthma. Am Rev Respir Dis 1991;144:1297-301.

24. Sekiya K, Nakatani E, Fukutomi Y, et al. Severe or life-threatening asthma exacerbation: patient heterogeneity identified by cluster analysis. Clin Exp Allergy 2016;46:1043-55.

25. Tommola M, IImarinen P, Tuomisto LE, et al. Differences between asthma-COPD overlap syndrome and adult-onset asthma. Eur Respir $J$ 2017;49:1602383.

26. Mitsunobu F, Ashida K, Hosaki Y, et al. Influence of long-term cigarette smoking on immunoglobulin E-mediated allergy, pulmonary function, and high-resolution computed tomography lung densitometry in elderly patients with asthma. Clin Exp Allergy 2004;34:59-64.

27. Juusela M, Pallasaho P, Rönmark E, et al. Dose-dependent association of smoking and bronchial hyperresponsiveness. Eur Respir J 2013;42:1503-12.

28. Kanner RE, Connett JE, Altose MD, et al. Gender difference in airway hyperresponsiveness in smokers with mild COPD. The Lung Health Study. Am J Respir Crit Care Med 1994:150:956-61.

29. McGeachie MJ, Yates KP, Zhou X, et al. Patterns of growth and decline in lung function in persistent childhood asthma. N Engl $J$ Med 2016;374:1842-52.

30. Hancox RJ, Gray AR, Poulton R, et al. The effect of cigarette smoking on lung function in young adults with asthma. Am J Respir Crit Care Med 2016;194:276-84.

31. Eisner MD, Yelin EH, Katz PP, et al. Predictors of cigarette smoking and smoking cessation among adults with asthma. Am J Public Health 2000;90:1307-11.

32. Vuolo M, Staff J. Parent and child cigarette use: a longitudinal, multigenerational study. Pediatrics 2013;132:e568-77.

33. Feleszko W, Zawadzka-Krajewska A, Matysiak K, et al. Parental tobacco smoking is associated with augmented IL-13 secretion in children with allergic asthma. J Allergy Clin Immunol 2006;117:97-102.

34. Ronchetti R, Macri F, Ciofetta G, et al. Increased serum IgE and increased prevalence of eosinophilia in 9-year-old children of smoking parents. J Allergy Clin Immunol 1990;86:400-7. 